\title{
Occupational noise exposure in manufacturing industries in Malaysia
}

\author{
Noraita Tahir ${ }^{*}$, Syed Mohamed Aljunid, Jamal Hisham Hashim \\ From 7th Postgraduate Forum on Health Systems and Policies \\ Phitsanulok, Thailand. 24-25 June 2013
}

\section{Background}

Manufacturing sector accounts for $18.1 \%$ of the total employed persons in Malaysia, which is known for the utilisation of noisy machinery to establish output. Even though it is compulsory for employers to notify any hearing loss cases to the authority annually, there is still scarcity of occupational hearing loss cases. Therefore, this study aimed to estimate the total number of workers exposed to occupational noise among workers in manufacturing industries in Malaysia.

\section{Materials and methods}

A field survey was carried out at 26 selected industries in five states Johor, Selangor, Pulau Pinang, Terengganu and Pahang that recorded highest noise induced hearing loss (NIHL) cases in 2011. Safety and Health Practitioners in each industry were interviewed and elicited information on the industrial classification, occupational noise management and level of exposure to workers. Noise exposures were categorised from noise exposure monitoring report. The percentage of high risk workers in each class was derived to estimate the number of exposed workers based on the Economic Census.

\section{Results}

Levels of occupational noise exposure among industries were $28 \%$ for $91-140 \mathrm{dBA}$ and $72 \%$ for $86-90 \mathrm{dBA}$; which classified that all workforces were at high risk. Occupational noise-exposed workers were observed to be highest in the metal industry (2091) followed by textile (631) and food (439). The percentage of workers exposed ranged from $13.6 \%$ to as high as $68.9 \%$ in each industry. In addition 103,673 (39\%) from total employment of 267,964 were estimated to be workers exposed to high risk noise.

\footnotetext{
* Correspondence: noraita.tahir@gmail.com

United Nations University International Institute for Global Health (UNU-IIGH), 56000 Cheras, Kuala Lumpur, Malaysia
} 